\title{
The interaction between nitrogen and phosphorous is a strong predictor of intra-plant variation in nitrogen isotope composition in a desert species
}

\author{
Jinxin Zhang ${ }^{1,2}$, Lianhong $\mathbf{G u}^{3}$, Jingbo Zhang ${ }^{1,4}$, Rina Wu${ }^{1}$, Feng Wang ${ }^{1}$, Guanghui Lin ${ }^{5}, \mathbf{B o} \mathbf{W u}^{1}$, Qi Lu ${ }^{1}$, and \\ Ping Meng 6 \\ ${ }^{1}$ Institute of Desertification Studies, Chinese Academy of Forestry, Beijing, China \\ ${ }^{2}$ Research Institute of Forestry, Chinese Academy of Forestry, Beijing, China \\ ${ }^{3}$ Environmental Sciences Division and Climate Change Science Institute, Oak Ridge National Laboratory, \\ Oak Ridge, TN 37831, USA \\ ${ }^{4}$ The Experimental Center of Desert Forestry of the Chinese Academy of Forestry, Dengkou, Inner Mongolia \\ Autonomous Region, China \\ ${ }^{5}$ Center for Earth System Science, Tsinghua University, Beijing, China \\ ${ }^{6}$ Headquarters, Chinese Academy of Forestry, Beijing, China
}

Correspondence to: Lianhong Gu (lianhong-gu@ornl.gov)

Received: 28 May 2016 - Published in Biogeosciences Discuss.: 6 June 2016

Revised: 24 November 2016 - Accepted: 10 December 2016 - Published: 11 January 2017

\begin{abstract}
Understanding intra-plant variations in $\delta^{15} \mathrm{~N}$ is essential for fully utilizing the potential of $\delta^{15} \mathrm{~N}$ as an integrator of the terrestrial nitrogen $(\mathrm{N})$ cycle and as an indicator of the relative limitation of $\mathrm{N}$ and phosphorous (P) on plant growth. Studying such variations can also yield insights into $\mathrm{N}$ metabolism by plant as a whole or by specific organs. However, few researchers have systematically evaluated intra-plant variations in $\delta^{15} \mathrm{~N}$ and their relationships with organ nutrient contents. We excavated whole plant architectures of Nitraria tangutorum Bobrov, a $\mathrm{C}_{3}$ species of vital regional ecological importance, in two deserts in northwestern China. We systematically and simultaneously measured $\mathrm{N}$ isotope ratios and $\mathrm{N}$ and $\mathrm{P}$ contents of different parts of the excavated plants. We found that intra-plant variations in $\delta^{15} \mathrm{~N}$ of $N$. tangutorum were positively correlated with corresponding organ $\mathrm{N}$ and $\mathrm{P}$ contents. However, it was the $\mathrm{N} \times \mathrm{P}$ interaction, not $\mathrm{N}$ and $\mathrm{P}$ individually or their linear combination, that was the strongest predictor of intra-plant $\delta^{15} \mathrm{~N}$. Additionally, we showed that root $\delta^{15} \mathrm{~N}$ increased with depth into soil, a pattern similar to profiles of soil $\delta^{15} \mathrm{~N}$ reported by previous studies in different ecosystems. We hypothesized that the strong positive intra-plant $\delta^{15} \mathrm{~N}-\mathrm{N}$ and $\mathrm{P}$ relationships are caused by three processes acting in conjunc-
\end{abstract}

tion: (1) $\mathrm{N}$ and $\mathrm{P}$ content-driven fractionating exchanges of ammonia between leaves and the atmosphere (volatilization) during photorespiration, (2) resorption and remobilization of $\mathrm{N}$ and $\mathrm{P}$ from senescing leaves, and (3) mixture of the retranslocated foliar $\mathrm{N}$ and $\mathrm{P}$ with existing pools in stems and roots. To test our hypothesis, future studies should investigate plant $\mathrm{N}$ volatilization and associated isotope fractionation and intra-plant variations in $\delta^{15} \mathrm{~N}$ in different species across ecosystems and climates.

\section{Introduction}

Nitrogen $(\mathrm{N})$ is the most limiting nutrient in many terrestrial ecosystems, especially those in temperate and boreal regions (Vitousek, 1994). As atmospheric $\mathrm{CO}_{2}$ concentrations continue to increase due to anthropogenic fossil fuel emissions, the limiting effects of $\mathrm{N}$ on ecosystem productivity may become increasingly important (Luo et al., 2004; Thornton et al., 2007; Sun et al., 2014). Understanding the $\mathrm{N}$ cycle is essential to forecasting and predicting ecosystem dynamics in response to climate change. Plant $\mathrm{N}$ acquisition, transformation, and translocation are key steps in $\mathrm{N}$ cycling be- 
cause they subsequently affect plant photosynthesis, growth, and substrate supply for microbial activities (Manzoni et al., 2010; Vitousek et al., 2010). Many physical, biological and chemical processes that control plant $\mathrm{N}$ acquisition, transformation, and translocation discriminate against $\mathrm{N}$ isotope 15 $\left({ }^{15} \mathrm{~N}\right)$ in favor of $\mathrm{N}$ isotope $14\left({ }^{14} \mathrm{~N}\right)$. As a result, the variations in the relative abundance of ${ }^{15} \mathrm{~N}$ to ${ }^{14} \mathrm{~N}$, quantified as $\delta^{15} \mathrm{~N}$, of plants contain rich information about these processes (Högberg, 1997; Robinson, 2001; Evans, 2001; Dawson et al., 2002). For this reason, $\delta^{15} \mathrm{~N}$ is often considered an integrator of terrestrial $\mathrm{N}$ cycling, and numerous studies have analyzed natural variations in plant $\delta^{15} \mathrm{~N}$ across disturbance and successional stages (e.g., Hobbie et al., 2000; Wang et al., 2007; Resco et al., 2011; Hyodo et al., 2013), climate and topoedaphic gradients (e.g., Austin and Sala, 1999; Schulze et al., 1998; Martinelli et al., 1999; Amundson et al., 2003; Craine et al., 2005, 2009; Bai et al., 2009), species (e.g., Cernusak et al., 2009; Gubsch et al., 2011), and types of mycorrhizal fungi (Hobbie and Hobbie, 2008; Hobbie and Högberg, 2012). Other studies have used $\delta^{15} \mathrm{~N}$ as an indicator of relative $\mathrm{N}$ and phosphorus (P) availability and limitation on plant growth (McKee et al., 2002; Wigand et al., 2007; Inglett et al., 2007; Mayor et al., 2014). These studies have demonstrated the power of using natural variations in $\delta^{15} \mathrm{~N}$ to understand physical and biological processes controlling $\mathrm{N}$ cycling in terrestrial ecosystems.

Compared with the prolific studies on variations in $\delta^{15} \mathrm{~N}$ across ecological and climate gradients and species, fewer studies have systematically evaluated intra-plant variations in $\delta^{15} \mathrm{~N}$. Studies that did examine intra-plant variations in $\delta^{15} \mathrm{~N}$ were often conducted in controlled environments. Most such studies focused on differences between roots and leaves. It has been found that leaves of a plant tended to be enriched in ${ }^{15} \mathrm{~N}$ compared with the roots of the same plant (Bergersen et al., 1988; Yoneyama and Kaneko, 1989; Evans et al., 1996; Kolb and Evans, 2002) and the difference can be as high as $7 \%$ which has the same magnitude as variations across ecological and climate gradients. Such large intra-plant variations in $\delta^{15} \mathrm{~N}$, if not accounted for, may confound interpretation of large-scale patterns in variations of $\delta^{15} \mathrm{~N}$ (Evans, 2001) and lead to misguided diagnoses of relative $\mathrm{N}$ and $\mathrm{P}$ limitation on plant growth. Nevertheless, no foliar enrichment or mixed results have also been observed both in controlled experiments (Evans et al., 1996; Hobbie et al., 2008) and in natural environments (Dijkstra et al., 2003).

Several mechanisms have been proposed to explain intraplant variations in $\delta^{15} \mathrm{~N}$ or lack thereof. The most commonly discussed mechanisms invoke the differences in the assimilation and transport of inorganic $\mathrm{N}$ of nitrate $\left(\mathrm{NO}_{3}^{-}\right)$and ammonium $\left(\mathrm{NH}_{4}^{+}\right)$within plants. Both the assimilation of $\mathrm{NO}_{3}^{-}$ and $\mathrm{NH}_{4}^{+}$discriminate against ${ }^{15} \mathrm{~N}$ (Yoneyama et al., 2003; Karsh et al., 2012; Table 1 in Johnson and Berry (2013) lists values for various isotope effects) but fundamental differences exist in their metabolism in plants. $\mathrm{NO}_{3}^{-}$is assimilated by nitrate reductase (NR) in a process that involves first the reduction of $\mathrm{NO}_{3}^{-}$to nitrite and then to $\mathrm{NH}_{4}^{+}$and finally to amino acids. This process can take place in roots, stems, and leaves (Masclaux-Daubresse et al., 2010). Consequently organic $\mathrm{N}$ compounds originated from $\mathrm{NO}_{3}^{-}$may come from assimilation events that take place in different parts of the plant (Evans et al., 1996; Evans, 2001). The discrimination by NR in roots leads to an enriched pool of unassimilated $\mathrm{NO}_{3}^{-}$, which is then transported to other parts of the plant via the transpiration stream of xylem. Thus leaves and shoots are expected to be enriched in ${ }^{15} \mathrm{~N}$ compared with roots when $\mathrm{NO}_{3}^{-}$is the source of nitrogen. This enrichment has been found to be correlated with the transpiration efficiency of the $\mathrm{N}$ acquisition (Cernusak et al., 2009).

The impact of $\mathrm{NH}_{4}^{+}$assimilation on intra-plant variations in $\delta^{15} \mathrm{~N}$ was traditionally thought to be minimal but more recent studies indicate that this might not be the case. $\mathrm{NH}_{4}^{+}$ is usually the most important source of $\mathrm{N}$ available to plant roots in natural terrestrial ecosystems (Schjoerring et al., 2002) although $\mathrm{NO}_{3}^{-}$and $\mathrm{NH}_{4}^{+}$are often available together (Bijlsma et al., 2000). $\mathrm{NH}_{4}^{+}$is also produced by plants as a central intermediate in a wide variety of metabolic processes such as $\mathrm{NO}_{3}^{-}$assimilation, photorespiration, lignin biosynthesis, protein turnover, and degradation of transport amides (Joy, 1988; Massad et al., 2010; Flechard et al., 2013). However, $\mathrm{NH}_{4}^{+}$is toxic to plants at high concentration (Britto and Kronzucker, 2002). Because of this, early workers assumed that once absorbed by roots, it is immediately assimilated in roots by the glutamine synthetase/glutamate synthase (GSGOGAT) pathway. This assumption led to a further hypothesis that organic $\mathrm{N}$ compounds derived from $\mathrm{NH}_{4}^{+}$ultimately result from a single assimilation event which occurred in roots, and therefore no intra-plant variation in $\delta^{15} \mathrm{~N}$ should occur for plants that have grown with $\mathrm{NH}_{4}^{+}$as the sole nitrogen source (e.g., Evans et al., 1996). However, later studies depict a much more complicated picture of assimilation and transport of $\mathrm{NH}_{4}^{+}$within plants. This complication involves two aspects. First, it has been found that a significant amount of $\mathrm{NH}_{4}^{+}$can be transported in the xylem from roots to shoots and the $\mathrm{NH}_{4}^{+}$pools in the apoplast in general and leaf tissues in particular can respond rapidly to the supply of $\mathrm{NH}_{4}^{+}$solution to the roots (Mattsson and Schjoerring, 2002; Schjoerring et al., 2002). Second, a recent modeling study suggests that the photorespiration-induced exchange of ammonia $\left(\mathrm{NH}_{3}\right)$ between leaves and the atmosphere, which has a large isotope effect (the isotope effect for molecular diffusion of $\mathrm{NH}_{3}$ is 1.0176 in still air and 1.0117 in leaf boundary layer; Farquhar et al., 1983), can substantially influence plant and atmospheric $\mathrm{N}$ isotopic compositions (Johnson and Berry, 2013). This process has been mostly ignored in previous studies of terrestrial variations in $\delta^{15} \mathrm{~N}$. Thus it appears that the impact of $\mathrm{NH}_{4}^{+}$assimilation and transport, as well as the $\mathrm{NH}_{3}$ exchange with the atmosphere during photorespira- 
tion on intra-plant variations in $\delta^{15} \mathrm{~N}$, may have been underestimated.

Besides the mechanisms discussed above, other fractionating processes such as transamination, redistribution of relatively enriched or depleted metabolites, differential losses of $\mathrm{N}$ from plant organs, and resorption and remobilization of $\mathrm{N}$ from senescing leaves have been suggested as potential causes of intra-plant variations in $\delta^{15} \mathrm{~N}$ (Evans, 2001; Werner and Schmidt, 2002; Cernusak et al., 2009; Tcherkez, 2011; Gauthier et al., 2013). In particular, fractionations in metabolic reactions (e.g., amino acid syntheses) and transfers of isotopically different plant metabolites across plant organs have been highlighted as factors contributing to intraplant heterogeneities in $\delta^{15} \mathrm{~N}$ (Gauthier et al., 2013).

Thus, there is a strong need for systematical evaluation of $\delta^{15} \mathrm{~N}$ variation across different organs within the same plant. Such evaluations will provide key guidance for using $\delta^{15} \mathrm{~N}$ as an integrator of terrestrial $\mathrm{N}$ cycling and as an indicator of relative nutrient limitation. They will also offer important insights into plant $\mathrm{N}$ metabolism. The present study represents a step in this direction. Our objective is to conduct the first measurement-based systematic evaluation of intra-plant variations in $\delta^{15} \mathrm{~N}$ and to shed light on potential mechanisms. We attempt to achieve this objective by comprehensively and simultaneously analyzing variations in $\delta^{15} \mathrm{~N}$ with carbon $(\mathrm{C})$, $\mathrm{N}$, and $\mathrm{P}$ contents in different plant organs with excavated whole architectures of a desert species grown in natural conditions.

The joint analysis of $\mathrm{N}$ and $\mathrm{P}$ is important for understanding variations in $\delta^{15} \mathrm{~N}$. These two elements are stoichiometrically coupled in plants (Gusewell, 2004). P availability affects plant photosynthesis and growth which may have implication for $\delta^{15} \mathrm{~N}$ variations in plants. For example, orthophosphate is a key reactant in photosynthetic carbon assimilation in chloroplasts and its supply directly affects the rates of carboxylation and photorespiration (Sivak and Walker, 1986; Kondracka and Rychter, 1997). Since fractionation occurs in foliar $\mathrm{NH}_{3}$ exchanges with the atmosphere during photorespiration (Johnson and Berry, 2013), an effect of P on plant nitrogen isotope composition can be expected. Another consideration is that the relative availability of $\mathrm{N}$ vs. $\mathrm{P}$ to plants has consequences on $\mathrm{N}$ isotope fractionation. This is because of two factors. First, no fractionation can occur if all available $\mathrm{N}$ is assimilated, which may happen when $\mathrm{N}$ is limiting (Cernusak et al., 2009; Gauthier et al., 2013). Second, P availability affects when and where $\mathrm{N}$ limitation occurs (Vitousek et al., 2010). Indeed, previous studies have found that $\mathrm{P}$ availability is correlated with $\delta^{15} \mathrm{~N}$ in plant biomass. For example, Major et al. (2014) showed that long-term additions of both $\mathrm{N}$ and $\mathrm{P}$ reduced foliar $\delta^{15} \mathrm{~N}$ compared with $\mathrm{N}$ or $\mathrm{P}$ additions alone in a lowland tropical rainforest. Studies such as this are the basis for the suggestion that $\delta^{15} \mathrm{~N}$ could be used as an indicator of ecosystem P limitation (McKee et al., 2002; Wigand et al., 2007; Inglett et al., 2007; Mayor et al., 2014).
The present study builds upon the earlier efforts reviewed above and fills a gap in systematic investigation of intra-plant variations in $\delta^{15} \mathrm{~N}$. We will demonstrate that the intra-plant variations in $\delta^{15} \mathrm{~N}$ in our study species Nitraria tangutorum Bobrov are closely related to organ $\mathrm{N}$ and $\mathrm{P}$ contents and their interaction. We will show that the intra-plant $\delta^{15} \mathrm{~N}-\mathrm{N}$ and $\mathrm{P}$ relationships found in our study cannot be readily explained with mechanisms thought to be responsible for $\delta^{15} \mathrm{~N}$ variations across species, ecological, and climate gradients. To stimulate future research in intra-plant $\delta^{15} \mathrm{~N}$ variations, we will propose a new, testable hypothesis that we believe most logically explains such variations.

\section{Materials and methods}

\subsection{Nitraria tangutorum Bobrov and the study sites}

We previously described in detail the biological and environmental characteristics of $N$. tangutorum and the study sites (Zhang et al., 2015). For convenience and completeness, some of the information presented in Zhang et al. (2015) is repeated here. $N$. tangutorum is a spiny $\mathrm{C}_{3}$ shrub species in the Nitraria genus of the Zygophyllaceae family. It is endemic to northwestern deserts in China with a distribution including northeastern Tibet, Gansu, Qinghai, Xinjiang, western Inner Mongolia, western Ningxia, and northern Shaanxi. It is a pioneer species of high tolerance to a variety of stresses. N. tangutorum controls local landscape evolution, owing to its exceptional capability of fixing sands and building sand dunes known as nebkhas or coppice dunes around its extensive shoot and root systems (Baas and Nield, 2007; Lang et al., 2013; Li et al., 2013). The formation process of nebkha was described in Zhang et al., (2015). The phytogenic nebkha dunes formed by $N$. tangutorum prevent or slow down sand movement, making it often the most ecologically important species in its environment. The height of a $N$. tangutorum nebkha typically ranges from 1 to $3 \mathrm{~m}$ and some may reach $5 \mathrm{~m}$. The base of a nebkha often has the shape of an ellipse with the major axis parallel to the local prevailing wind direction (Fig.1). Below the base are dense clay layers that constitute dried-up flat beds of previous rivers or lakes. The nebkha-building characteristic of $N$. tangutorum makes it relatively easy to excavate the whole plant including roots for isotope and nutrient analyses except for a small fraction of roots that have grown into the solid clay layers below the base of nebkha and require some efforts to dig them out. Previously we studied intra-plant variations in carbon isotope composition of this species (Zhang et al., 2015). Wang et al. (2014) studied the variations of its foliar and root nitrogen and phosphorous contents in season and along aridity gradients. To our knowledge, this species has never been investigated for intra-plant variation in $\delta^{15} \mathrm{~N}$, whether in cultures or in natural environments. 


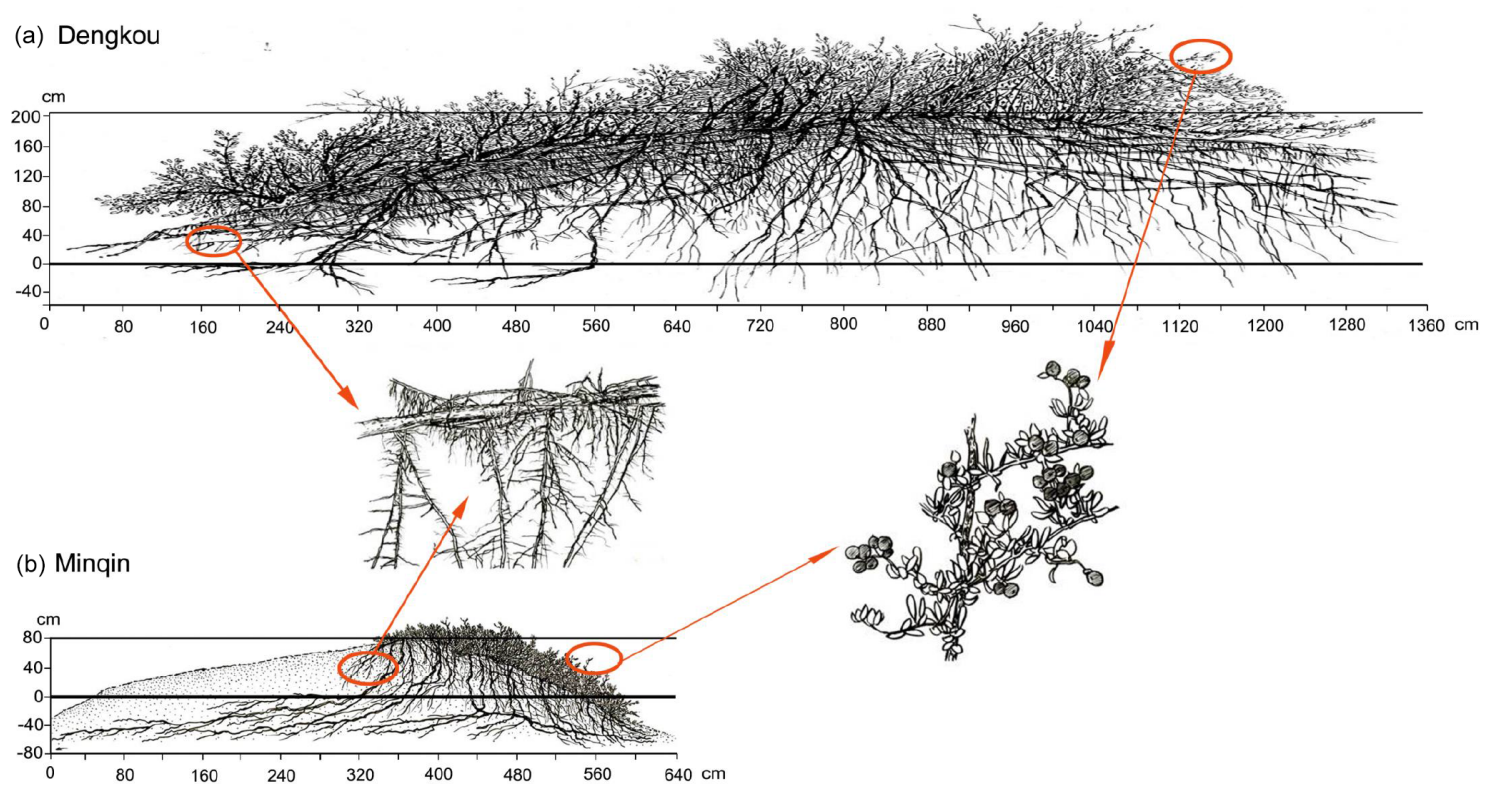

Figure 1. Pen drawings of typical nebkha formed by Nitraria tangutorum Bobrov at the Dengkou (a) and Minqin (b) study sites. The scales shown are for illustrative purposes only and therefore are not very precise.

Our field work was carried out in two desert locations. The first site was in Dengkou County, Inner Mongolia Autonomous Region, China. Dengkou County is at the junction between the Hetao Plain and Ulan Buh Desert of the Mongolian Plateau in the middle reaches of the Yellow River. The mean annual temperature is $8.84^{\circ} \mathrm{C}$ and the mean annual precipitation is $147 \mathrm{~mm}$ with $77.5 \%$ of annual rainfall occurring from June to September (1983-2012 averages). The mean annual potential evaporation is $2381 \mathrm{~mm}$ (Li et al., 2013). The sampling was conducted within an experimental area $\left(40^{\circ} 24^{\prime} \mathrm{N}, 106^{\circ} 43^{\prime} \mathrm{E}\right)$ managed by the Experimental Center of Desert Forestry of the Chinese Academy of Forestry. The study site has sandy soil and gray-brown desert soil (Cambic Arenosols and Luvic Gypsisols in FAO taxonomy). The $N$. tangutorum nebkhas in the area are formed on clay soils deposited by the Yellow River. Although the plant community is dominated by $N$. tangutorum, xerophytic species such as semi-shrub Artemisia ordosica, perennial grass Psammochloa villosa, and annual species Agriophyllum squarrosum and Corispermum mongolicum can also be found.

The second study site was in Minqin County, Gansu Province, China. Minqin County is located in the lower reaches of Shiyang River, surrounded by the Badain Jaran Desert in the west and north and the Tengger Desert in the east. The mean annual temperature is $8.87^{\circ} \mathrm{C}$ and the mean annual precipitation is $117 \mathrm{~mm}$ with $73.1 \%$ of annual rainfall occurring from June to September (1983-2012 averages). The mean annual potential evaporation is $2643 \mathrm{~mm}$ (Du et al., 2010). Thus the second study site is somewhat drier than the first site but with similar annual mean temperatures. The sampling was conducted within the Gansu Minqin Desert Ecosystem Research Station $\left(38^{\circ} 34^{\prime} \mathrm{N}, 102^{\circ} 58^{\prime} \mathrm{E}\right)$. The soil at the Minqin site is similar to that at the Dengkou site, with sandy soil in the nebkhas and gray-brown desert soil between nebkhas. The native vegetation is usually dominated by shrubs and semi-shrubs, with species such as $N$. tangutorum and Calligonum mongolicum. Experimental plots used in this study contained semi-fixed nebkha dunes developed by the growth of $N$. tangutorum. Typically in dry years, $N$. tangutorum is the only species growing in the nebkhas, although in wet years annual species such as Agriophyllum squarrosum and Corispermum mongolicum can also be found. Because the Minqin site is drier than the DengKou site, the nebkhas at the Minqin site are generally smaller and less populated with plants than at the Dengkou site. The rooting depth is deeper at the Minqin site than at the Dengkou site (see Table 1 in Zhang et al., 2015). Nitrogen cycling at these remote desert sites has rarely been studied. We are not aware of any previous report that indicates $N$. tangutorum or any co-existing species might be a nitrogen fixer. Throughout our investigation, we found no evidence of any nitrogen fixer existing at the two study sites. We did not investigate whether there might be any nitrogen-fixing symbionts in $N$. tangutorum. However, there was a single conference report on the observation of the presence of endogenous nitrogen-fixing bacteria in a related species $N$. schoberi (Li et al., 2015). Therefore it is possible that $N$. tangutorum might also have nitrogen-fixing symbionts. Nevertheless, soil is probably the primary source of nitrogen for $N$. tangutorum at our study sites. Since the present study focuses on intra-plant varia- 
tions in $\delta^{15} \mathrm{~N}$, the nature of nitrogen source is not critically important for our study.

\subsection{Excavation of Nitraria tangutorum nebkhas}

In August 2012, three nebkhas were excavated at each study site. The geometrical and biometrical characteristics of the six nebkhas were summarized in Table 1 of Zhang et al. (2015). At the Dengkou site, the three nebkhas were excavated in a sampling area of $40 \mathrm{~m} \times 40 \mathrm{~m}$. At the Minqin site, nebkhas were generally much smaller. To ensure availability for analyses of sufficient biomass materials at this site, particularly the fine roots (see below), three sampling areas, each with a dimension of $30 \mathrm{~m} \times 30 \mathrm{~m}$, were established and three nebkhas from each sampling area were tentatively excavated. Two nebkhas from one sampling area and one from another were deemed to have sufficient amount of fine roots for analyses and were therefore excavated fully. The nebkhas were excavated by carefully teasing away the sands from the mounds to expose the root architecture of $N$. tangutorum with particular attention paid to preserving its fine roots and to distinguishing any roots from other plant species that may happen to grow in the same nebkhas. The roots of a $N$. tangutorum plant can be found inside the sand mounds as well as inside the clay layer that generally forms a plain on which the sand mounds rest. We therefore also excavated any roots inside the clay layer to a depth under which no more roots could be found. Only biomass materials from $N$. tangutorum were harvested and any materials from all other species that may be present were excluded to ensure pure intra-plant analyses required by this study.

We separated the whole plant biomass into groups of leaves, stems, in-sand roots, and below-plain roots. The insand roots, which were roots found inside the nebkha sands but above the plain formed by the underlying clay layer, were further separated into in-sand fine roots (diameter $\leq 2 \mathrm{~mm}$ ) and in-sand coarse roots (diameter $>2 \mathrm{~mm}$ ). The same root diameter threshold was used to separate the below-plain roots, which were found inside the clay layer under the nebkha sands. Furthermore, the below-plain fine and coarse roots were grouped in a $20 \mathrm{~cm}$ depth increment from the plain surface. We did not separate the in-sand fine and coarse roots into layers because a nebkha has a cone shape on top, making a layer hard to define. Also we did not use a simple "below-ground" group because "ground" is not well defined in a nebkha-populated landscape and because there are large physical and chemical differences between sands and clay which may affect the isotope compositions of roots growing in them. Litter was rarely found on the nebkhas, presumably because strong winds at the study sites can easily blow away any litter produced. However, woody debris from dead ramets was present inside the sand mounds and was collected during excavation. Thus for each nebkha, we differentiated the following categories of $N$. tangutorum biomass for intra-plant isotope analyses: leaves, stems, in-sand fine roots (ISFR), in-sand coarse roots (ISCR), below-plain fine roots (BPFR) in $20 \mathrm{~cm}$ depth increments, below-plain coarse roots (BPCR) in $20 \mathrm{~cm}$ increments, and woody debris (WD). Nutrient contents and nitrogen isotope compositions were measured separately for each category.

\subsection{Measurements of nutrient contents and nitrogen isotope compositions with excavated biomass}

All categories of $N$. tangutorum biomass (leaves, stems, ISFR, ISCR, BPFR in $20 \mathrm{~cm}$ increments, BPCR in $20 \mathrm{~cm}$ increments, and WD) from each excavated nebkha were dried to constant weight $\left(60^{\circ}, 48 \mathrm{~h}\right)$. The dry weight of biomass was determined with $0.01 \mathrm{~g}$ accuracy on an analytical scale. Dried materials were randomly sampled from each biomass category and ground to 80 mesh in Tyler Standard Sieve Series $(0.177 \mathrm{~mm}$ opening). The resultant powder was separated into six duplicates. Three duplicates were analyzed for $\mathrm{C}, \mathrm{N}$, and $\mathrm{P}$ contents and the remaining three for isotope compositions. The $\mathrm{C}, \mathrm{N}$, and $\mathrm{P}$ contents were measured in the Environmental Chemistry Analysis Laboratory in the Institute of Geographic Sciences and Natural Resources Research, the Chinese Academy of Sciences, Beijing, China. Total sample carbon and $\mathrm{N}$ were measured with the vario MACRO cube (Elementar Company, Germany). The analytical precision was better than $0.5 \%$ relative standard deviation (RSD). Total P was measured with the ICP-OES OPTIMA 5300DV (PE, USA). A wet digestions method was applied in the analysis (Webb and Adeloju, 2013). Sample preparation and assaying followed standard procedures per instrument instruction. The analytical precision was better than $2 \%$ RSD.

The nitrogen isotope compositions were analyzed at the Stable Isotope Ratio Mass Spectrometer Laboratory of the Chinese Academy of Forestry (SIRMSL, CAF), Beijing, China. The instrument used was a Delta V Advantage Mass Spectrometer (Thermo Fisher Scientific, Inc., USA) coupled with an elemental analyzer (FlashEA 1112; HT Instruments, Inc., USA) in the continuous flow mode. Isotope compositions were expressed using the delta notation $(\delta)$ in parts per thousand (\%o $): \delta^{15} \mathrm{~N}(\% o)=\left[\left(R_{\text {sample }}\right) /\left(R_{\text {standard }}\right)-\right.$ $1] \times 1000$, where $R$ is the molar ratio of ${ }^{15} \mathrm{~N}$ to ${ }^{14} \mathrm{~N}$. The measurement applied the IAEA-600 standard (Caffeine) relative to atmosphere $\mathrm{N}_{2}$. The analytical precision was better than $0.2 \%$ based on replicate measurements of the reference standard.

\subsection{Statistical analyses}

Two-way ANOVA analyses (organ by site) were performed with SPSS (Ver.17.0). C, N, and P contents, $\delta^{15} \mathrm{~N}, \mathrm{C} / \mathrm{N}$ ratios, $\mathrm{N} / \mathrm{P}$ ratios, and $\mathrm{C} / \mathrm{P}$ ratios were analyzed for differences between organs and between study sites. All ratios were mass-based. Tukey post-hoc tests were used to determine pairwise differences for significant effects $(P<0.05)$. Linear and multilinear regression analyses were used to de- 
termine the relationships between the organ $\delta^{15} \mathrm{~N}$ and nutrient contents. Due to the strong correlation between organ contents of different nutrients (Zhang et al., 2015) and therefore the potential presence of multicollinearity, we used stepwise regression to determine the most significant predictor(s) (including interaction) of intra-plant variations in $\delta^{15} \mathrm{~N}$. Both forward and backward methods were used in the stepwise regression with F-to-enter and F-to-remove set at 4.0 $(P=0.05)$ and $3.9(P=0.052)$, respectively. All $P$ values for regression slope analyses were computed on a two-tailed basis.

Our regressional analyses were based on fixed effects models. Fixed effects models are appropriate for the present study because we attempt to explain variations in $\delta^{15} \mathrm{~N}$ as a function of non-random explanatory variables such as $\mathrm{C}$, $\mathrm{N}$, and $\mathrm{P}$ contents and their ratios (mixed or random effects models are used more commonly in social sciences, Cameron and Trivedi, 2005). We are only interested in the detection of the existence or absence of any potential correlation between the specific effect (nitrogen isotope composition) and explanatory variables across plant organs, and we are not interested in how any peculiarities of nebkas and locations might or might not affect the specific effect. Nevertheless, we did analyze the data from the two study sites separately and came to similar conclusions. Therefore, to increase the statistic power of our analyses (i.e., to avoid using data from a single nebka at a single location and getting a spurious correlation), we pooled the data together but with sites and organs clearly marked in figures so that patterns for individual sites and organs can be seen clearly.

\section{Results}

\subsection{Variations in $\delta^{15} \mathrm{~N}$ among plant organs and between study sites}

For comparing $\delta^{15} \mathrm{~N}$ among plant organs and between sites (Fig. 2), we averaged the duplicate mean of each organ across the three nebkhas at each site. Results for comparisons of nutrient values were already presented in Zhang et al. (2015) and thus not repeated here. There were considerable variations in $\delta^{15} \mathrm{~N}$ values among plant organs and between study sites. At both the Dengkou and Minqin sites, leaves had positive $\delta^{15} \mathrm{~N}$ and were enriched in ${ }^{15} \mathrm{~N}$ compared with corresponding stems and roots at the same site. Also, at both sites, the $\delta^{15} \mathrm{~N}$ value of fine root followed the same order: ISFR $<1 F R<2 F R<3 F R<4 F R$; i.e., it increased with depth into soil. Here 1FR, 2FR, FR, and 4FR refer to fine roots in 0-20, 20-40, 40-60, and $60-80 \mathrm{~cm}$ soil depths, respectively. The same pattern was repeated for the $\delta^{15} \mathrm{~N}$ value of coarse root; the only exception was $2 \mathrm{CR}$ (coarse root at a soil depth of 20 to $40 \mathrm{~cm}$ ) at the Dengkou site which dropped out of the general order. The $\delta^{15} \mathrm{~N}$ values of fine roots at the Dengkou site were consistently higher than the corresponding coarse roots both inside the nebkha sands and below the

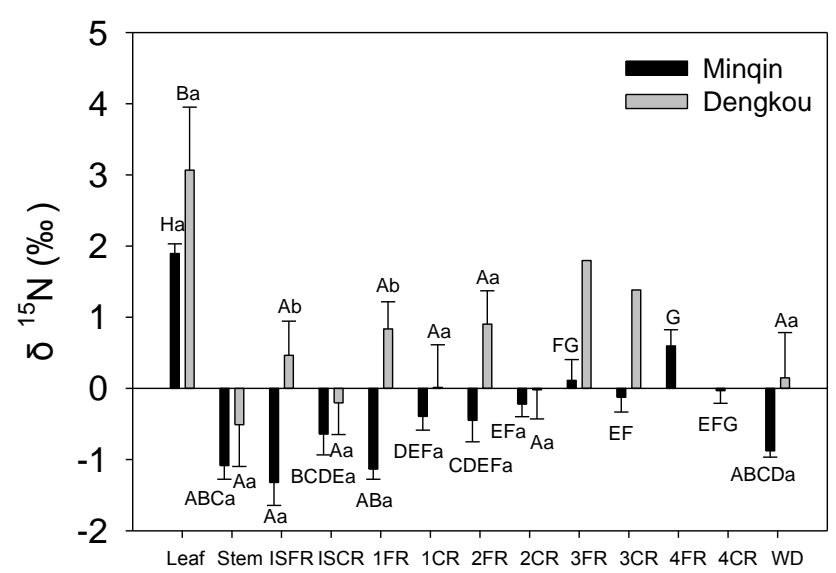

Figure 2. A comparison of $\delta^{15} \mathrm{~N}$ among different plant organs of Nitraria tangutorum Bobrov and between the Dengkou and Minqin study sites. The $\delta^{15} \mathrm{~N}$ value shown is averaged for each organ across the nebkhas excavated at the same site (Dengkou or Minqin). Upper-case letters denote ANOVA results within a study site (i.e., comparing $\delta^{15} \mathrm{~N}$ among different organs at the same site) and lower-case letters between the two sites (i.e., comparing $\delta^{15} \mathrm{~N}$ of the same organ between the two sites). ISFR and ISCR stand for fine and coarse roots, respectively, in the sands of nebkhas. 1FR, 2FR, 3FR, and 4FR stand for fine roots at 0-20, 20-40, 40-60, and $60-80 \mathrm{~cm}$ depths, respectively, below the plains on which nebkhas rest. Similarly, 1CR, 2CR, 3CR, and 4CR stand for coarse roots within these depth intervals. Fine and coarse roots are differentiated with a diameter threshold of $2 \mathrm{~mm}$. Woody debris (WD) from dead ramets is also included in the figure. No ANOVA results for 3FR and 3CR at the Dengkou site as there was only one nebkha having roots between 40 and $60 \mathrm{~cm}$. No roots were found below $60 \mathrm{~cm}$ at the Dengkou site.

plain of the same site. In contrast, at the Minqin site, the $\delta^{15} \mathrm{~N}$ values of fine roots were consistently less than the corresponding coarse roots except for the roots deep into the plain $(40-80 \mathrm{~cm})$ where the fine root was more enriched. At the Dengkou site, the stem had the lowest $\delta^{15} \mathrm{~N}$ while at the Minqin site, the ISFR had the lowest $\delta^{15} \mathrm{~N}$. At both sites, the $\delta^{15} \mathrm{~N}$ value in the woody debris was greater than the corresponding stem although the difference was not statistically significant. The foliar $\delta^{15} \mathrm{~N}$ at the Dengkou site was higher than at the Minqin site. In fact, in all biomass categories investigated, the $\delta^{15} \mathrm{~N}$ value at the Dengkou site was greater than its corresponding counterpart at the Minqin site. The $\delta^{15} \mathrm{~N}$ values of plant organs at the Dengkou site were mostly positive while at the Minqin site, the values were mostly negative. Unfortunately, these site differences cannot be attributed in the present study since we did not measure potential sources of nitrogen, particularly soil nitrogen, at the two study sites. 

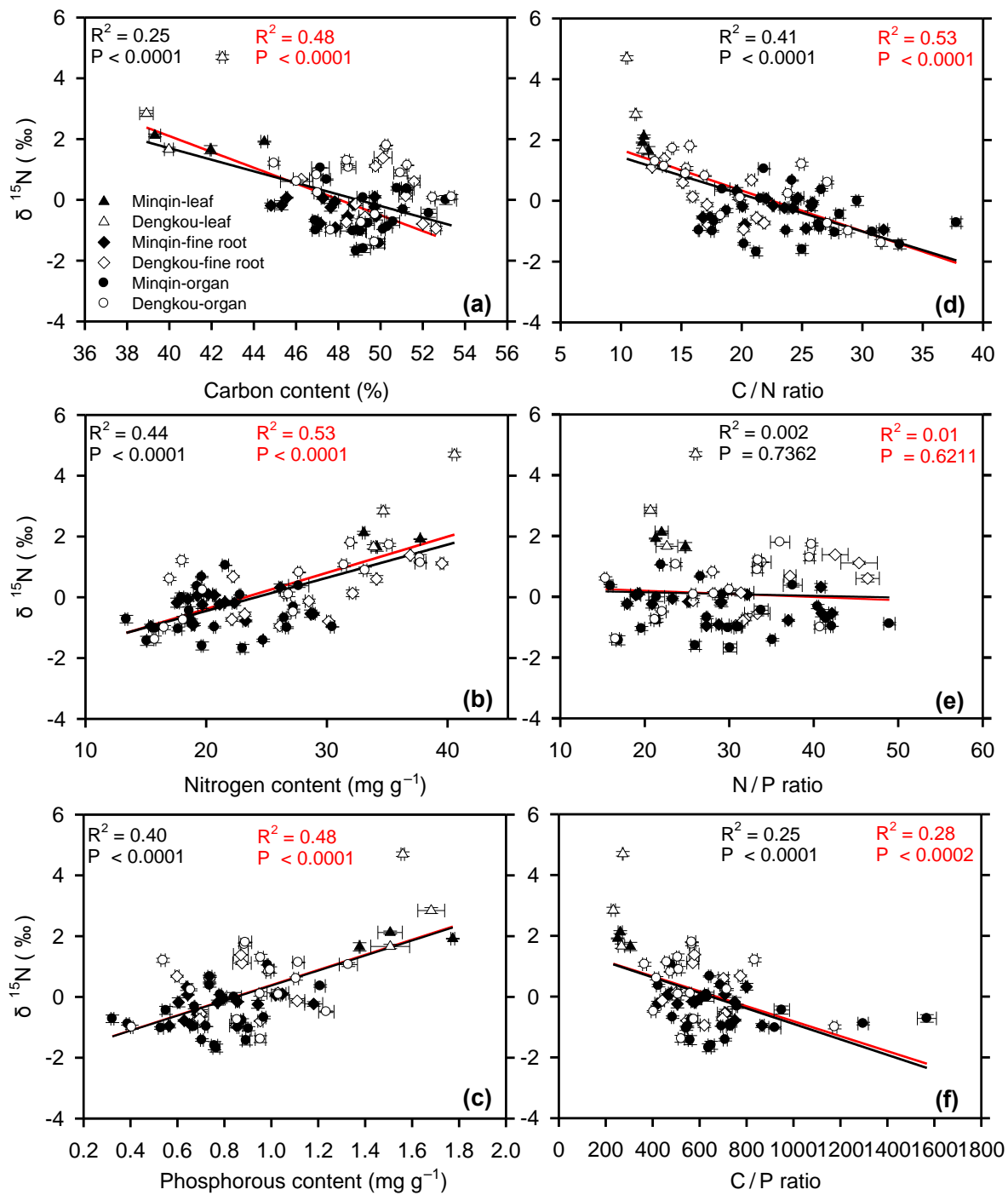

Figure 3. Changes of $\delta^{15} \mathrm{~N}$ as a function of organ contents of carbon (a), nitrogen (b), and phosphorous (c) and of organ ratios of carbon to nitrogen (d), nitrogen to phosphorous (e), and carbon to phosphorus (f). Filled and unfilled symbols represent organs at the Minqin and Dengkou sites, respectively. Leaves are denoted by filled or unfilled triangles while other organs by filled or unfilled circles. The black regression lines are for all organs while for the red regression lines, data of fine roots are not included.

\subsection{Intra-plant relationships between $\delta^{15} \mathrm{~N}$ and nutrient concentrations}

Even though intra-plant and between-site variations in $\delta^{15} \mathrm{~N}$ were large, these variations were unified in relationships with organ nutrient contents (Fig. 3). The large intra-plant variations in $\delta^{15} \mathrm{~N}(\sim 7 \%$ at the Dengkou site and $4 \%$ o at the Minqin site), as well as in organ nitrogen and phosphorous contents, facilitated regression analyses between these variables. Because the intra-plant relationships were not significantly different between the two study sites, we pooled the data from the two sites in regression analyses. We found that intraplant variations in $\delta^{15} \mathrm{~N}$ were significantly correlated with the organ contents of carbon (Fig. $3 \mathrm{a}, R^{2}=0.25, P<0.0001$ ), nitrogen (Fig. $3 \mathrm{~b}, \mathrm{R}^{2}=0.44, P<0.0001$ ), and phosphorous (Fig. 3 c, $R^{2}=0.40, P<0.0001$ ) and with the organ ratios of carbon to nitrogen (Fig. 3d, $R^{2}=0.41, P<0.0001$ ) and carbon to phosphorous (Fig. 3f, $R^{2}=0.25, P<0.0001$ ). The correlations were positive with organ nitrogen and phosphorous contents but negative with the carbon content and the carbon-to-nitrogen and carbon-to-phosphorous ratios. No correlation with the organ nitrogen-to-phosphorous ratios was found (Fig. 3e).

Although intra-plant variations in $\delta^{15} \mathrm{~N}$ were significantly correlated with organ nitrogen and phosphorous contents, both forward and backward stepwise regressions consistently identified the interaction between nitrogen and phosphorous contents as the most significant predictor of intra-plant vari- 


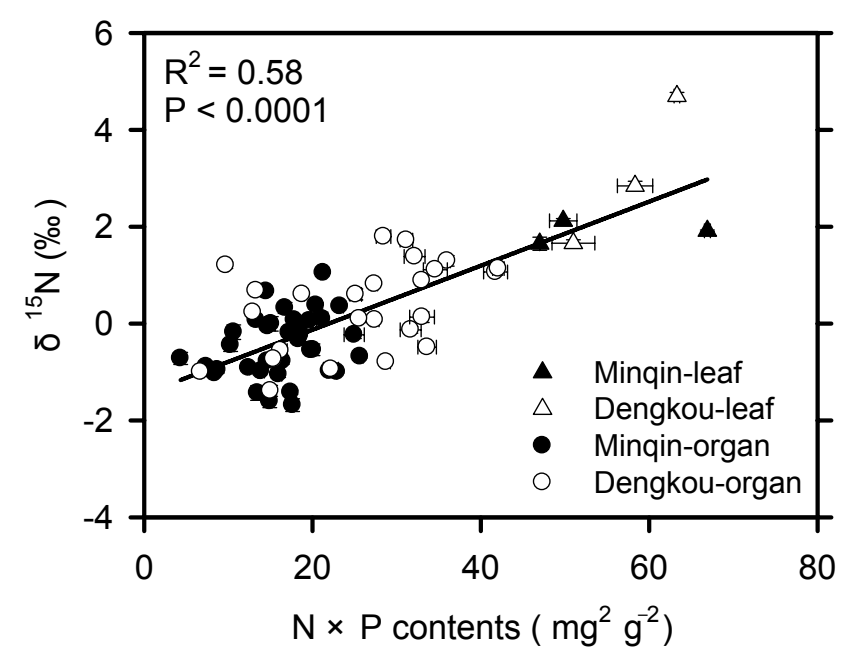

Figure 4. Changes of $\delta^{15} \mathrm{~N}$ as a function of the product of organ $\mathrm{N} \times \mathrm{P}$ contents. Filled and unfilled symbols represent organs at the Minqin and Dengkou site, respectively. Leaves are denoted by filled or unfilled triangles while other organs by filled or unfilled circles.

ation in $\delta^{15} \mathrm{~N}\left(R^{2}=0.58, P<0.0001\right.$, Fig. 4). Adding organ nitrogen content or phosphorous content, or both, did not significantly improve the predictive ability of resultant equations.

Since fine roots differ from other organs in that fine roots are the primary organs for nitrogen acquisition, we recalculated the organ $\delta^{15} \mathrm{~N}$-nutrient relationships by removing all fine roots from the analyses, which are shown as the red regression lines in Fig. 3. We found that all correlations became stronger (compare the red with black regression lines in Fig. 3). In addition, because leaves had considerably higher $\delta^{15} \mathrm{~N}$ and nutrient contents than other organs, we similarly re-calculated the correlations by removing leaves from the analyses to avoid a foliar domination of the obtained relationships. After the leaves were removed, all correlations were still significant (data not shown, but can be seen from Figs. 3 and 4). Furthermore, the removal of either leaves or fine roots did not alter the finding that the $\mathrm{N} \times \mathrm{P}$ interaction was the strongest predictor of intra-plant variations in $\delta^{15} \mathrm{~N}$. Thus the intra-plant $\delta^{15} \mathrm{~N}$-nutrient relationships appeared to be generic and independent of specific physiological or metabolic functions of particular plant organs.

\section{Discussion}

\subsection{Potential mechanisms for the observed intra-plant $\delta^{15} \mathrm{~N}-\mathrm{N}$ and $\mathrm{P}$ relationships}

This study appears to be the first to report that the strongest predictor of intra-plant variation in $\delta^{15} \mathrm{~N}$ is the interaction between organ $\mathrm{N}$ and $\mathrm{P}$ contents rather than $\mathrm{N}$ or $\mathrm{P}$ themselves or their linear combination. To our knowledge, no previous studies have evaluated relationships between intra-plant vari-

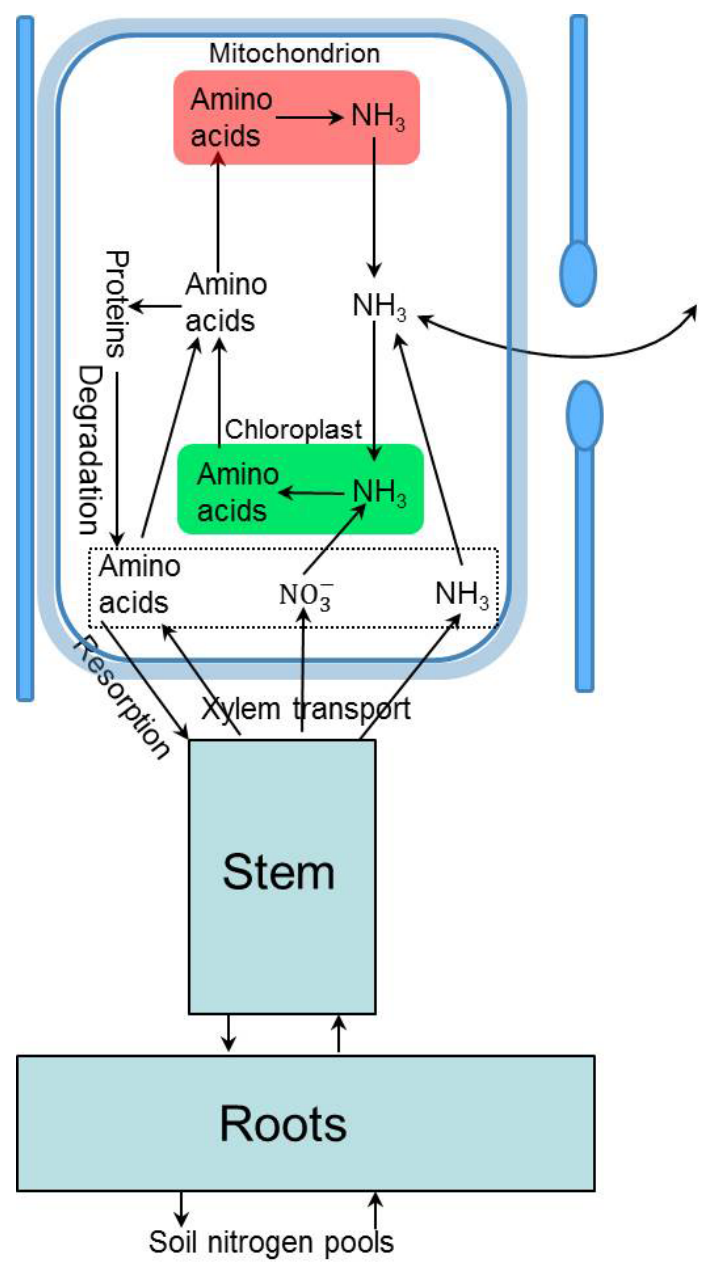

Figure 5. Intra-plant nitrogen cycling and flux exchanges with external environments.

ations in $\delta^{15} \mathrm{~N}$ and organ $\mathrm{N}$ or $\mathrm{P}$ contents through systematical measurement approaches, although models have been developed to simulate root-shoot differences in $\delta^{15} \mathrm{~N}$ in responses to overall changes in nitrogen supply and demand (e.g., Kalcsits et al., 2014). What mechanism(s) could be responsible for such close relationships? Clearly this question cannot be answered conclusively with data available in this study or existing data in other published studies. Here we propose a hypothesis based on a synthesis of best available knowledge (Fig. 5). We hope our hypothesis will provide a starting point for follow-up research.

To facilitate our discussion, we group potential mechanisms into three categories: external factors only, internal factors only, and external and internal factors together. Potential external factors include different sources of nitrogen (e.g., $\mathrm{NO}_{3}^{-}, \mathrm{NH}_{4}^{+}$, organic nitrogen, $\mathrm{N}_{2}$ fixation). Because the patterns are observed across different organs of the same plants, rather than across different plants in different environments, an external-factors-only explanation cannot be the responsible mechanism. An internal-factors-only explanation 
requires a $\mathrm{N}$ and $\mathrm{P}$ allocation mechanism that allocates these two key nutrients roughly in proportion to $\delta^{15} \mathrm{~N}$ in plant organs and at the same time keeps the isotopic mass balance for the whole plant. Translocation of nitrogenous solutes (e.g., $\mathrm{NO}_{3}^{-}, \mathrm{NH}_{4}^{+}$, amino acids) is a mass-flow process and mainly takes place from roots to shoots to leaves via xylem and from leaves to shoots to roots via phloem, but lateral transfer between xylem and phloem may also occur (Simpson, 1986; Bijlsma et al., 2000). $\delta^{15} \mathrm{~N}$ values probably originate mostly from fractionations in primary assimilation and exchange events and in subsequent metabolic reactions that create ${ }^{15} \mathrm{~N}$-enriched or ${ }^{15} \mathrm{~N}$-depleted metabolites (Tcherkez, 2011; Gauthier et al., 2013). The translocated nitrogenous compounds mix with existing structural (e.g., nitrogen in cell wall) or functional (e.g., nitrogen in photosynthesis, respiration, and storage that can readily mobilize and take part in metabolic reactions) nitrogen of an organ to give a bulk signal in $\delta^{15} \mathrm{~N}$. It is conceptually difficult to imagine how these numerous, loosely coupled processes internal to plants collude to produce coordinated variations in $\mathrm{N}, \mathrm{P}$, and $\delta^{15} \mathrm{~N}$ across different plant organs. Therefore the probability that an internal-factors-only mechanism causes the observed patterns is likely very small. In the following, we focus on the possibility that external and internal factors work together to create the observed intra-plant variations in $\delta^{15} \mathrm{~N}$.

Plants can emit a vast number of nitrogenous compounds to the atmosphere, which is known to affect atmospheric secondary aerosol formation and climate (Sintermann and Neftel, 2015). These compounds are formed in metabolic processes such as the decarboxylation and transamination of amino acids (Bagni and Tassoni, 2001; Dudareva et al., 2013). Emissions of these compounds from fruits and flowers are readily noticed without needing sensitive measurements. In addition to fruits and flowers, leaves and stems can also emit nitrogenous compounds. Like many physical and biochemical processes, it is probably not unreasonable to assume that fractionation occurs in the emission of nitrogenous compounds from plants. Unfortunately no isotope fractionation measurements have ever been made on the emission of most of these compounds. However, considerable isotopic knowledge exists in the plant-atmosphere exchange of $\mathrm{NH}_{3}$.

As shown in Fig. 5, $\mathrm{NH}_{3}$ is a key link between plant metabolism and ambient air (Flechard et al., 2013). As discussed in the Introduction, living plant organs contain liquid pools of $\mathrm{NH}_{4}^{+}$maintained by nitrogen translocation, nitrate and nitrite reduction, photorespiration, and other metabolic processes. In these pools, the rapid protonationdeprotonation process sustains an equilibrium between $\mathrm{NH}_{4}^{+}$ and aqueous $\mathrm{NH}_{3}$. In the apoplast, gaseous $\mathrm{NH}_{3}$ is in equilibration with aqueous $\mathrm{NH}_{3}$ across air-liquid interfaces (e.g., in the intercellular airspace), depending on the concentration ratio $(\Gamma)$ of $\mathrm{NH}_{4}^{+}$to $\mathrm{H}^{+}$and therefore apoplastic $\mathrm{pH}$ (Flechard et al., 2013; Johnson and Berry et al., 2013). Isotope effects occur when the apoplast is able to exchange $\mathrm{NH}_{3}$ with ambient atmosphere. The fractionation has been estimated to be
$17.6 \%$ for diffusion through still air and $11.7 \%$ o through boundary layer (Farquhar et al., 1983; Johnson and Berry, 2013).

We are not aware of any reports that stems and aerial roots may emit or absorb $\mathrm{NH}_{3}$. However, it is a widely established fact that leaves exchange $\mathrm{NH}_{3}$ with atmosphere through stomata (Farquhar et al., 1980; Wetselaar and Farquhar, 1980; Farquhar et al., 1983; Sharpe and Harper, 1997; Johnson and Berry, 2013; Flechard et al., 2013; Sintermann and Neftel, 2015). So for the momentum, let us focus on leaves (Figs. 3 and 4). The exchange can be bi-directional, depending on the gradient in the concentration of $\mathrm{NH}_{3}$ across stomata. If the ambient concentration of $\mathrm{NH}_{3}$ is above the stomatal compensation point of $\mathrm{NH}_{3}$ ( $\chi$, Farquhar et al., 1980), absorption occurs; otherwise, emission takes place. $\chi$ is directly related to $\Gamma$ which in turn is a function of leaf nitrogen content (Flechard et al., 2013). This is because nitrogen-containing proteins (enzymes) are critical to photorespiration, which releases $\mathrm{NH}_{3}$ due to the decarboxylation of glycine in mitochondria (Keys, 2006). If leaf nitrogen is high and therefore the photorespiration rate is high, the re-assimilation by glutamine synthetase may not be fast enough to keep all $\mathrm{NH}_{3}$ released from the mitochondria internal to the metabolic cycles, leading to emission of $\mathrm{NH}_{3}$ from leaves. This emission will result in ${ }^{15} \mathrm{~N}$-enriched pools in leaves. Conversely, if leaf nitrogen is low and therefore the photorespiration rate is low, ambient $\mathrm{NH}_{3}$ may diffuse into leaves, making leaf nitrogen pools more ${ }^{15} \mathrm{~N}$ depleted. Thus a positive foliar $\delta^{15} \mathrm{~N}-\mathrm{N}$ relationship can be predicted. This prediction is supported by empirical evidence. For example, Gauthier et al. (2013) showed that foliar nitrate content is positively correlated with foliar $\delta^{15} \mathrm{~N}$ in Brassica napus $\mathrm{L}$.

But how can we explain the positive $\delta^{15} \mathrm{~N}-\mathrm{P}$ relationship and the even better $\delta^{15} \mathrm{~N}-\mathrm{N} \times \mathrm{P}$ relationship? Again, for the moment, we focus on leaves. We believe the answer lies in the role that phosphate $\left(\mathrm{P}_{\mathrm{i}}\right)$ plays in photosynthesis and photorespiration. The photosynthetic reaction in chloroplasts is described by $3 \mathrm{CO}_{2}+6 \mathrm{H}_{2} \mathrm{O}+\mathrm{P}_{\mathrm{i}} \rightarrow$ triose phosphate $+3 \mathrm{H}_{2} \mathrm{O}+3 \mathrm{O}_{2}$. Chloroplasts import $\mathrm{P}_{\mathrm{i}}$ from and export triose phosphate to cytosol to sustain this reaction. $\mathrm{P}_{\mathrm{i}}$ deficiency can limit the maximum electron transport rate in thylakoid membranes (Sivak and Walker, 1986) and therefore photorespiration rate and $\mathrm{NH}_{3}$ concentration in sub-stomatal cavities under full sunlight. Conversely, increased $P_{i}$ supply may boost photorespiration and $\mathrm{NH}_{3}$ concentration. As a result, foliar $\delta^{15} \mathrm{~N}$ should be positively related to $\mathrm{P}$, just as it should be positively related to $\mathrm{N}$. Why can $\delta^{15} \mathrm{~N}$ be predicted even better by $\mathrm{N} \times \mathrm{P}$ ? This is because a stoichiometry is needed between $\mathrm{N}$ and $\mathrm{P}$ to keep an efficient operation of the photosynthetic machinery (Gusewell, 2004), i.e., an oversupply of $\mathrm{N}$ cannot compensate for a deficiency in $\mathrm{P}$ and vice versa.

Our emphasis on photorespiration in the relationships of foliar $\delta^{15} \mathrm{~N}$ with $\mathrm{N}, \mathrm{P}$, and $\mathrm{N} \times \mathrm{P}$ should be evaluated in the context of the enormous importance of leaves in the nitrogen 
metabolism of the whole plant. While roots are the primary gate for outside nitrogen to enter into the internal nitrogen cycle, leaves are the 'theater' of nitrogen 'actions' within the plant. It is estimated that in $\mathrm{C}_{3}$ species, mesophyll chloroplasts may contain as much as $75 \%$ of total cellular nitrogen in a plant (Hörtensteiner and Feller, 2002). A major portion of leaf nitrogen is involved in photosynthetic reactions; $\mathrm{Ru}-$ BisCO alone, which catalyzes carboxylation and oxygenation, accounts for 15 to $30 \%$ of total leaf nitrogen (Evans, 1989). More importantly, the flux of $\mathrm{NH}_{3}$, which is released by photorespiration and subject to either re-assimilation into amino acids or emission into the atmosphere, is 5 to 10 times larger than the primary assimilation rate at roots (Keys, 2006; Masclaux-Daubresse et al., 2010). The fraction of emission to the atmosphere depends on a range of biotic and abiotic factors. In measurements on two rice cultivars, Kumagai et al. (2011) reported that 12 and $21 \%$ respectively of leaf nitrogen was lost to the atmosphere due to release of $\mathrm{NH}_{3}$ in photorespiration. Thus it seems possible for the leaf-atmosphere exchange of $\mathrm{NH}_{3}$ to fundamentally affect the relationships of foliar $\delta^{15} \mathrm{~N}$ with $\mathrm{N}, \mathrm{P}$, and $\mathrm{N} \times \mathrm{P}$ as the model of Johnson and Berry (2013) has suggested.

It is more challenging to include stems and roots in the equation. Clearly a photorespiration-based mechanism alone is not sufficient to explain the observed overall relationships as they hold across leaves, stems, and roots (Figs. 3 and 4). Assuming there are no $\mathrm{N}$-and-P-mediated fractionating processes that directly exchange nitrogenous compounds between stems (and roots) and the ambient air, is it possible for the leaf-atmosphere exchanges of nitrogen isotopes to affect $\delta^{15} \mathrm{~N}$ values in stems and roots such that $\delta^{15} \mathrm{~N}$ increases with $\mathrm{N}, \mathrm{P}$, and $\mathrm{N} \times \mathrm{P}$ across the whole plant as depicted in Figs. 3 and 4 ?

We believe it is possible. Mature leaves export nitrogen and phosphorous to other organs of plants (e.g., Aerts, 1996; Killingbeck, 1996; Jeschke et al., 1997; Hörtensteiner and Feller, 2002; Masclaux-Daubresse et al., 2010; Brant and Chen, 2015). In particular, plants resorb and remobilize essential nutrients to storage tissues in stems and roots during leaf senescence. In this process, proteins, particularly those involved in photosynthesis, are degraded, providing an enormous source of mobile nutrients. Resorption and remobilization of nutrients from senescing leaves are a vital strategy for plant survival for multiple reasons. First, it requires energy to absorb and assimilate new nutrients from soil solutions, and thus recycling extant nutrients makes economic sense. Second, nutrient availability in the soil may be low and the rate of absorption at the root-soil interface may not be able to meet the instantaneous demand by new growth in the next spring. In a survey of published values, Brant and Chen (2015) found that leaf nitrogen and phosphorus resorption efficiencies are generally over $60 \%$ for a wide variety of plant species ranging from grasses and forbs to deciduous and evergreen trees (see Table 1 in that paper). Franklin and Ågren (2002) showed that a $70 \%$ leaf nitrogen resorption efficiency is needed to predict observed leaf area indices of several plant communities. Because of methodological limitations, these estimates do not generally consider volatilization losses to the atmosphere and thus are considered "apparent remobilization" (Masclaux-Daubresse et al., 2010). Nevertheless, there is little doubt that foliar nitrogen metabolism can affect stem and root nitrogen status. The foliar nitrogen and phosphorus remobilized to storage organs will support the growth of not only new leaves but also new tissues in stems and roots. Given that large amounts of $\mathrm{N}$ and $\mathrm{P}$ participate in reactions in leaves and are processed through leaves, it is reasonable to assume that the relationships of $\delta^{15} \mathrm{~N}$ with $\mathrm{N}, \mathrm{P}$, and $\mathrm{N} \times \mathrm{P}$ in the stems and roots may bear a similarity to those of the leaves.

To summarize our fairly detailed reasoning above, the observed patterns in intra-plant variations in $\delta^{15} \mathrm{~N}$ appear to be most logically explained by the following three processes working together (Fig. 5):

- leaf-atmosphere exchanges of nitrogenous compounds, particularly $\mathrm{NH}_{3}$ released during photorespiration,

- nitrogen and phosphorus resorption and remobilization from senescing leaves, and

- mixture of resorbed and remobilized nitrogen and phosphorus with existing pools in stems and roots.

Nevertheless, we emphasize that this is a hypothesis only and it remains a research task to ascertain how $\mathrm{N}, \mathrm{P}$, and $\mathrm{N} \times \mathrm{P}$ affect the divergence of $\delta^{15} \mathrm{~N}$ in different organs of plants.

\subsection{Comparison with reported inter-plant relationships}

It is interesting to compare the intra-plant relationships found here with the previously reported correlations of foliar $\delta^{15} \mathrm{~N}$ with $\mathrm{N}$ across species, climate, and ecological gradients. The positive intra-plant correlation between $\delta^{15} \mathrm{~N}$ and $\mathrm{N}$ content reported in the present study is reminiscent of the foliar correlations reported in those previous studies. Using a dataset that contained over 11000 plants worldwide, Craine et al. (2009) found that foliar $\delta^{15} \mathrm{~N}$ was positively correlated with foliar N. A subset of this dataset contained $\delta^{15} \mathrm{~N}, \mathrm{~N}$, and $\mathrm{P}$ measurements. These authors subsequently analyzed this subset with a multilinear model that used N, P, and their interaction as explanatory variables. It was not clear whether multicollinearity was controlled but they found that after controlling for variations in $\mathrm{N}$, foliar $\delta^{15} \mathrm{~N}$ decreased with an increase in $\mathrm{P}$ and in $\mathrm{N} \times \mathrm{P}$. We used the same model to fit our intra-plant dataset without consideration of multicollinearity and found that foliar $\delta^{15} \mathrm{~N}$ decreased with both $\mathrm{N}$ and $\mathrm{P}$ but increased with $\mathrm{N} \times \mathrm{P}$. Thus controlling multicollinearity is important for ascertaining relationships between $\delta^{15} \mathrm{~N}$ and nutrient contents due to correlations between contents of different nutrients.

Positive foliar correlations of $\delta^{15} \mathrm{~N}$ with $\mathrm{N}$ have been reported in studies at smaller scales as well (e.g., Martinelli et 
al., 1999; Hobbie et al., 2000; Craine et al., 2005). In addition, Hobbie et al. (2008) reported a positive correlation for root tips. These positive correlations, which were all interrather than intra-plant in nature, are consistent with the reported experimental finding that an increase in soil nitrogen availability tends to lead to an increase in $\delta^{15} \mathrm{~N}$ of non- $\mathrm{N}$ fixing plants (Wigand et al., 2007; Hobbie et al., 2008; Mayor et al., 2014). A hypothesis based on plant-mycorrhizal fungus interactions has been advanced to explain this positive relationship (Hobbie et al., 2000; Craine et al., 2009; Hobbie and Högberg, 2012). Typically mycorrhizal fungi transfer isotopically depleted $\mathrm{N}$ to host plants. As soil $\mathrm{N}$ supply increases, the contribution from mycorrhizal symbionts to the total $\mathrm{N}$ budget of host plants may decrease, reducing the mycorrhizal dilution effect on the heavy isotope and resulting in a positive relationship of plant $\delta^{15} \mathrm{~N}$ with soil $\mathrm{N}$ supply. However, this explanation is only valid for $\delta^{15} \mathrm{~N}$ of the plant as a whole and cannot explain the positive relationship of intra-plant $\delta^{15} \mathrm{~N}$ with $\mathrm{N}$ and the interaction between $\mathrm{N}$ and $\mathrm{P}$. In addition to the mycorrhizal hypothesis, a more general explanation for the $\mathrm{N}$ supply-plant $\delta^{15} \mathrm{~N}$ relationship involves the openness of the $\mathrm{N}$ cycle. This explanation hypothesizes that an increase in $\mathrm{N}$ supply promotes the openness of the $\mathrm{N}$ cycle and the increased openness results in higher losses of ${ }^{14} \mathrm{~N}$ relative to ${ }^{15} \mathrm{~N}$ from the system, leading to enrichment in ${ }^{15} \mathrm{~N}$ in the remaining nitrogen pool. The openness typically refers to processes occurring in soil (e.g., $\mathrm{N}$ losses through denitrification via the release of $\mathrm{N}_{2} \mathrm{O}$ and $\mathrm{N}_{2}$ from soil which is a strong fractionating process, Mnich and Houlton, 2016). Clearly a soil-central $\mathrm{N}$ openness explanation is also not valid for the intra-plant $\delta^{15} \mathrm{~N}-\mathrm{N} \times \mathrm{P}$ relationship reported in this study.

Another possibility to consider concerns the situation when nitrate is the source of $\mathrm{N}$ for plants. If soil supply of nitrate is low, all nitrate absorbed by roots may be assimilated in the roots and no enriched nitrate pool is left for transport to other parts of the plant. As soil supply of nitrate increases, the proportion of the nitrate pool that is unassimilated by roots and thus is available for transport to other parts of the plant may not only increase in size but also become more enriched in ${ }^{15} \mathrm{~N}$ (a system cannot discriminate if all substrates are assimilated; discrimination generally increases with substrate availability, Evans, 2001). However, this possibility can only suggest that the difference in $\delta^{15} \mathrm{~N}$ between roots and the rest of the plant may increase with soil nitrate supply. It cannot account for the changes of $\delta^{15} \mathrm{~N}$ with organ $\mathrm{N}$ and $\mathrm{P}$ contents and their interaction within the plant.

We are not aware of any previous studies that systematically evaluated variations in root $\delta^{15} \mathrm{~N}$ with depth into soil. However, our finding that roots tend to become more enriched in ${ }^{15} \mathrm{~N}$ deeper into soil is reminiscent of the general patterns of increasing soil $\delta^{15} \mathrm{~N}$ with depth, as reported in previous studies (Hobbie and Ouimette, 2009; Gubsch et al., 2011; Szpak, 2014). Since the present study did not measure soil $\delta^{15} \mathrm{~N}$ profile, it remains to be determined whether the profile of root $\delta^{15} \mathrm{~N}$ reflects that of soil $\delta^{15} \mathrm{~N}$.

\section{Conclusion}

A systematical evaluation of nitrogen isotope composition in the desert plant species Nitraria tangutorum Bobrov reveals that the magnitude of intra-plant variations in $\delta^{15} \mathrm{~N}$ is close to the highest value reported in previous studies (7\%o, Fig. 3 and also Evans, 2001). These variations are positively correlated with corresponding organ $\mathrm{N}$ and $\mathrm{P}$ contents. However, it is the $\mathrm{N} \times \mathrm{P}$ interaction, not $\mathrm{N}$ and $\mathrm{P}$ individually or their linear combination, that is the strongest predictor of intra-plant $\delta^{15} \mathrm{~N}$. While the positive correlation of intra-plant $\delta^{15} \mathrm{~N}$ with organ $\mathrm{N}$ resembles the $\delta^{15} \mathrm{~N}-\mathrm{N}$ relationships reported in previous studies on patterns across ecological and climate gradients and across species, explanations developed from these previous studies are not valid for the patterns reported in the present study. We also report that root $\delta^{15} \mathrm{~N}$ increases with depth into soil. This pattern in root $\delta^{15} \mathrm{~N}$ is similar to profiles of soil $\delta^{15} \mathrm{~N}$ reported in previous studies, although the exact relationship between root and soil profiles in $\delta^{15} \mathrm{~N}$ is not clear. We hypothesize that the strong positive intra-plant $\delta^{15} \mathrm{~N}-\mathrm{N}$ and $\mathrm{P}$ relationships are a result of three processes working together: (1) N-and-P-driven, fractionating ammonia exchanges between leaves and the atmosphere (volatilization) during photorespiration, (2) resorption and remobilization of $\mathrm{N}$ and $\mathrm{P}$ from senescing leaves, and (3) mixture of re-translocated foliar $\mathrm{N}$ and $\mathrm{P}$ with existing pools in stems and roots.

Knowledge of how plants acquire, transport, and transform $\mathrm{N}$ is crucial for understanding how plants use this crucial resource for production, growth, and reproduction and how the terrestrial $\mathrm{N}$ cycle operates. Intra-plant variations in $\delta^{15} \mathrm{~N}$ are an important outcome of the $\mathrm{N}$ cycle. The findings reported in the present study suggest that different mechanisms may operate at different scales to affect plant nitrogen isotope compositions and their relationships with nutrient availability. Alternatively, causes of variations in $\delta^{15} \mathrm{~N}$, whether they are intra-plant, inter-species, or cross ecological and climate gradients, may differ from those previously considered. Our findings suggest that studies into intra-plant variations in $\delta^{15} \mathrm{~N}$ and their mechanisms can yield deep insights into the $\mathrm{N}$ cycle of ecosystem and plant nitrogen metabolism. Such studies have not been adequate in the past and are urgently needed.

\section{Data availability}

Data are available by contacting the author at lianhonggu@ornl.gov. 
Acknowledgements. Field work, data acquisition, and analyses were conducted at the Institute of Desertification Studies with support from the National Key Technology R\&D Program of the Ministry of Science and Technology of China (2012BAD16B01), the National Natural Science Foundation of China Youth Fund Project (31400620), the State Forestry Administration of China Forestry Public Welfare Scientific Research Funding (201404304), the Science and Technology Foundation (CAF201202), and the Lecture and Study Program for Outstanding Scholars from Home and Abroad of the Chinese Academy of Forestry (CAFYBB2011007). Data analyses and manuscript writing were partly carried out at Oak Ridge National Laboratory (ORNL) with support from US Department of Energy, Office of Science, Biological and Environmental Research Program, Climate and Environmental Sciences Division. ORNL is managed by UTBattelle, LLC, for the US Department of Energy under contract DE-AC05-00OR22725.

Edited by: N. Ohte

Reviewed by: three anonymous referees

\section{References}

Aerts, R.: Nutrient resorption from senescing leaves of perennials: are there general patterns?, J. Ecol., 84, 597-608, 1996.

Amundson, R., Austin, A. T., Schuur, E. A. G., Yoo, K., Matzek, V., Kendall, C., Uebersax, A., Brenner, D., and Baisden, W. T.: Global patterns of the isotopic composition of soil and plant nitrogen, Global Biogeochem. Cy., 17, 1031, doi:10.1029/2002GB001903, 2003.

Austin, A. T. and Sala, O. E.: Foliar $\delta^{15} \mathrm{~N}$ is negatively correlated with rainfall along the IGBP transect in Australia, Aust. J. Plant Physiol., 26, 293-295, 1999.

Baas, A. C. W. and Nield, J. M.: Modelling vegetated dune landscapes, Geophys. Res. Lett., 34, L06405, doi:10.1029/2006GL029152, 2007.

Bagni, N. and Tassoni, A.: Biosynthesis, oxidation and conjugation of aliphatic polyamines in higher plants, Amino Acids, 20, 301$317,2001$.

Bai, E., Boutton, T. W., Liu, F., Wu, X. B., Archer, S. R., and Hallmark, C. T.: Spatial variation of the stable nitrogen isotope ratio of woody plants along a topoedaphic gradient in a subtropical savanna, Oecologia, 159, 493-503, 2009.

Bergersen, F. J., Peoples, M. B., and Turner, G. L.: Isotopic discriminations during the accumulation of nitrogen by soybeans, Aust. J. Plant Physiol., 15, 407-420, 1988.

Bijlsma, R. J., Lambers, H., and Kooijman, S. A. L. M.: A dynamic whole-plant model of integrated metabolism of nitrogen and carbon. 1. Comparative ecological implications of ammoniumnitrate interactions, Plant Soil, 220, 49-69, 2000.

Brant, A. N. and Chen, Y. H.: Patterns and mechanisms of nutrient resorption in plants, CRC Cr. Rev. Plant Sci., 34, 471-486, 2015.

Britto, D. T. and Kronzucker, H. J.: $\mathrm{NH}_{4}^{+}$toxicity in higher plants: a critical review, J. Plant Physiol., 159, 567-584, 2002.

Cameron, A. C. and Trivedi, P. K.: Microeconometrics: Methods and Applications, Cambridge University Press, Cambridge, New York, USA, 717-719, 2005.
Cernusak, L. A., Winter, K., and Turner, B. L.: Plant $\delta^{15} \mathrm{~N}$ correlates with the transpiration efficiency of nitrogen acquisition in tropical trees, Plant Physiol., 151, 1667-1676, 2009.

Craine, J. M., Lee, W. G., Bond, W. J., Williams, R. J., and Johnson, L. C.: Environmental constraints on a global relationship among leaf and root traits of grasses, Ecology, 86, 12-19, 2005.

Craine, J. M., Elmore, A. J., Aidar, M. P. M., Bustamante, M., Dawson, T. E., Hobbie, E. A., Kahmen, A., Mack, M.C., McLauchlan, K. K., Michelsen, A., Nardoto, G. B., Pardo, L. H., Peñuelas, J., Reich, P. B., Schuur, E. A. G., Stock, W. D., Templer, P. H., Virginia, R. A., Welker, J. M., and Wright, I. J.: Global patterns of foliar nitrogen isotopes and their relationships with climate, mycorrhizal fungi, foliar nutrient concentrations, and nitrogen availability, New Phytol., 183, 980-992, 2009.

Dawson, T. E., Mambelli, S., Plamboeck, A. H., Templer, P. H., and Tu, K. P.: Stable isotopes in plant ecology, Annu. Rev. Ecol. Syst., 33, 507-559, 2002.

Dijkstra, P., Williamson, C., Menyailo, O., Kocha, G., and Hungatea, B. A.: Nitrogen stable isotope composition of leaves and roots of plants growing in a forest and a meadow, Isot. Environ. Health S., 39, 29-39, 2003.

$\mathrm{Du}$, J. H., Yan, P., and Dong, Y. X.: Phenological response of $\mathrm{Ni}$ traria tangutorum to climate change in Minqin County, Gansu Province, northwest China, Int. J. Biometeorol., 54, 583-593, 2010.

Dudareva, N., Klempien, A., Muhlemann, J. K., and Kaplan, I.: Biosynthesis, function and metabolic engineering of plant volatile organic compounds, New Phytol., 198, 16-32, 2013.

Evans, J. R.: Photosynthcsis and nitrogen relationships in leaves of C3 plants, Oecologia, 78, 9-19, 1989.

Evans, R. D.: Physiological mechanisms influencing plant nitrogen isotope composition, Trends Plant Sci., 6, 121-126, 2001.

Evans, R. D., Bloom, A. J., Sukrapanna, S. S., and Ehleringer, J. R.: Nitrogen isotope composition of tomato (Lycopersicon esculentum Mill. cv. T-5) grown under ammonium or nitrate nutrition, Plant Cell Environ., 19, 1317-1323, 1996.

Farquhar, G. D., Firth, P. M., Wetselaar, R., and Weir B.: On the gaseous exchange of ammonia between leaves and the environment: determination of the ammonia compensation point, Plant Physiol., 66, 710-714, 1980.

Farquhar, G. D., Wetselaar, R., and Weir, B.: Gaseous nitrogen losses from plants, in: Gaseous loss of nitrogen from plant-soil systems, edited by: Freney, J. R. and Simpson, J. R., Berlin, Germany, Springer Press, the Netherlands, 159-180, 1983.

Flechard, C. R., Massad, R.-S., Loubet, B., Personne, E., Simpson, D., Bash, J. O., Cooter, E. J., Nemitz, E., and Sutton, M. A.: Advances in understanding, models and parameterizations of biosphere-atmosphere ammonia exchange, Biogeosciences, 10, 5183-5225, doi:10.5194/bg-10-5183-2013, 2013.

Franklin, O. and Ågren, G. I.,: Leaf senescence and resorption as mechanisms of maximizing photosynthetic production during canopy development at N limitation, Funct. Ecol., 16, 727-733, 2002.

Gauthier, P. P. G., Lamothe, M., Mahe, A., Molero, G., Nogues, S., Hodges, M., and Tcherkez, G.: Metabolic origin of $\delta^{15} \mathrm{~N}$ values in nitrogenous compounds from Brassica napus L. leaves, Plant Cell Environ., 36, 128-137, 2013.

Gubsch, M., Roscher, C., Gleixner, G., Habekost, M., Lipowsky, A., Schmid, B., Schulze, E. D., Steinbeiss, S., and Buchmann, 
N.: Foliar and soil $\delta^{15} \mathrm{~N}$ values reveal increased nitrogen partitioning among species in diverse grassland communities, Plant Cell Environ., 34, 895-908, 2011.

Gusewell, S.: N:P ratios in terrestrial plants: variation and functional significance, New Phytol., 164, 243-266, 2004.

Hobbie, E. A. and Hobbie, J. E.: Natural abundance of ${ }^{15} \mathrm{~N}$ in nitrogen-limited forests and tundra can estimate nitrogen cycling through mycorrhizal fungi: a review, Ecosystems, 11, 815-830, 2008.

Hobbie, E. A. and Högberg, P.: Nitrogen isotopes link mycorrhizal fungi and plants to nitrogen dynamics, New Phytol., 196, 367382,2012

Hobbie, E. A. and Ouimette, A. P.: Controls of nitrogen isotope patterns in soil profiles, Biogeochemistry, 95, 355-371, 2009.

Hobbie, E. A., Macko, S. A., and Williams, M.: Correlations between foliar $\delta^{15} \mathrm{~N}$ and nitrogen concentrations may indicate plant mycorrhizal interactions, Oecologia, 122, 273-283, 2000.

Hobbie, E. A., Colpaert, J. V., White, M. W., Ouimette, A. P., and Macko, S. A.: Nitrogen form, availability, and mycorrhizal colonization affect biomass and nitrogen isotope patterns in Pinus sylvestris, Plant Soil, 310, 121-136, 2008.

Högberg, P.: Tansley Review No. $95{ }^{15} \mathrm{~N}$ natural abundance in soilplant systems, New Phytol., 137, 179-203, 1997.

Hörtensteiner, S. and Feller, U.: Nitrogen metabolism and remobilization during senescence, J. Exp. Bot., 53, 927-937, 2002.

Hyodo, F., Kusaka, S., Wardle, D. A., and Nilsson, M. C.: Changes in stable nitrogen and carbon isotope ratios of plants and soil across a boreal forest fire chronosequence, Plant Soil, 367, 111119,2013

Inglett, P. W., Reddy, K. R., Newman, S., and Lorenzen, B.: Increased soil stable nitrogen isotopic ratio following phosphorous enrichment: historical patterns and tests of two hypotheses in a phosphorous wetland, Oecologia, 153, 99-109, 2007.

Jeschke, W. D., Kirkby, E. A., Peuke, A. D., Pate, J. S., and Hartung, W.: Effects of $\mathrm{P}$ deficiency on assimilation and transport of nitrate and phosphate in intact plants of castor bean (Ricinus communis L.), J. Exp. Bot., 48, 75-91, 1997.

Johnson, J. E. and Berry, J. A.: The influence of leaf-atmosphere $\mathrm{NH}_{3(g)}$ exchange on the isotopic composition of nitrogen in plants and the atmosphere, Plant Cell Environ., 36, 1783-1801, 2013.

Joy, K. W.: Ammonia, glutamine and asparagine: a carbon-nitrogen interface, Can. J. Botany, 66, 2103-2109, 1988.

Kalcsits, L. A., Buschhaus, H. A., and Guy, R. D.: Nitrogen isotope discrimination as an integrated measure of nitrogen fluxes, assimilation and allocation in plants, Physiol. Plantarum, 151, 293-304, 2014.

Karsh, K. L., Granger, J., Kritee, K., and Sigman, D. M.: Eukaryotic assimilatory nitrate reductase fractionates $\mathrm{N}$ and $\mathrm{O}$ isotopes with a ratio near unity, Environ. Sci. Technol., 46, 5727-5735, 2012.

Keys, A. J.: The re-assimilation of ammonia produced by photorespiration and the nitrogen economy of $\mathrm{C}_{3}$ higher plants, Photosynth. Res., 87, 165-175, 2006.

Killingbeck, K. T.: Nutrients in senesced leaves: keys to the search for potential resorption and resorption proficiency, Ecology, 77, 1716-1727, 1996

Kolb, K. J. and Evans, R. D.: Implications of leaf nitrogen recycling on the nitrogen isotope composition of deciduous plant tissues, New Phytol., 156, 57-64, 2002.
Kondracka, A. and Rychter, A. M.: The role of $\mathrm{P}_{\mathrm{i}}$ recycling processes during photosynthesis in phosphate-deficient bean plants, J. Exp. Bot., 48, 1461-1468, 1997.

Kumagai, E., Araki, T., Hamaoka, N., and Ueno, O.: Ammonia emission from rice leaves in relation to photorespiration and genotypic differences in glutamine synthetase activity, Ann. Bot.-London, 108, 1381-1386, 2011.

Lang, L. L., Wang, X. M., Hasi, E., and Hua, T.: Nebkha (coppice dune) formation and significance to environmental change reconstructions in arid and semiarid areas, J. Geograph. Sci., 23, 344358, 2013.

Li, J. F., Du, J. X., and Zhang, S. Q.: The effects of sap of Nitraria plant on the growth of its endogenous nitrogen-fixing microbes under saline-alkaline stress, International Conference on Chemical, Material and Food Engineering (CMFE-2015), 25-26 July 2015, Kunming, China, 2015.

Li, Q. H., Xu, J., Li, H. Q., Wang, S. X., Yan, X., Xin, Z. M., Jiang, Z. P., Wang, L. L., and Jia, Z. Q.: Effects of aspect on clonal reproduction and biomass allocation of layering modules of Nitraria tangutorum in Nebkha dunes, PLOS One, 8, e79927, doi:10.1371/journal.pone.0079927, 2013.

Luo, Y., Su, B. O., Currie, W. S., Dukes, J. S., Finzi, A., Hartwig, U., Hungate, B., McMurtrie, R. E., Oren, R., Parton, W. J., Pataki, D. E., Shaw, R. M., Zak, D. R., and Field, C. B.: Progressive nitrogen limitation of ecosystem responses to rising atmospheric carbon dioxide, Bioscience, 54, 731-739, 2004.

Manzoni, S., Trofymow, J. A., Jackson, R. B., Porporato, A.: Stoichiometric controls on carbon, nitrogen, and phosphorus dynamics in decomposing litter, Ecol. Monogr., 80, 89-106, 2010.

Martinelli, L. A., Piccolo, M. C., Townsend, A. R., Vitousek, P. M., Cuevas, E., Mcdowell, W., Robertson, G. P., Santos, O. C., and Treseder, K.: Nitrogen stable isotopic composition of leaves and soil: tropical versus temperate forests, in: New Perspectives on Nitrogen Cycling in the Temperate and Tropical Americas, edited by: Townsend, A. R., Berlin, Germany, Springer Press, the Netherlands, 45-65, 1999.

Masclaux-Daubresse, C., Daniel-Vedele, F., Dechorgnat, J., Chardon, F., Gaufichon, L., and Suzuki A.: Nitrogen uptake, assimilation and remobilization in plants: challenges for sustainable and productive agriculture, Ann. Bot.-London, 105, 11411157, 2010.

Massad, R.-S., Nemitz, E., and Sutton, M. A.: Review and parameterisation of bi-directional ammonia exchange between vegetation and the atmosphere, Atmos. Chem. Phys., 10, 10359-10386, doi:10.5194/acp-10-10359-2010, 2010.

Mattsson, M. and Schjoerring, J. K.: Dynamic and steady-state responses of inorganic nitrogen pools and $\mathrm{NH}(3)$ exchange in leaves of Lolium perenne and Bromus erectus to changes in root nitrogen supply, Plant Physiol., 128, 742-750, 2002.

Mayor, J. R., Wright, S. J., Schuur, E. A. G., Brooks, M. E., and Turner, B. L.: Stable nitrogen isotope patterns of trees and soils altered by long-term nitrogen and phosphorus addition to a lowland tropical rainforest, Biogeochemistry, 119, 293-306, 2014.

McKee, K. L., Feller, I. C., Popp. M. P., and Wanek, W.: Marianne Popp and Wolfgang Wanek Mangrove isotopic ( $\delta 15 \mathrm{~N}$ and $\delta 13 \mathrm{C})$ fractionation across a nitrogen vs. phosphorus limitation gradient, Ecology, 83, 1065-1075, 2002.

Mnich, M. E. and Houlton, B. Z.: Evidence for a uniformly small isotope effect of nitrogen leaching loss: results from disturbed 
ecosystems in seasonally dry climates, Oecologia, 181, 323-333, 2016.

Resco, V., Ferrio, J. P., Carreira, J. A., Calvo, L., Casals, P., FerreroSerrano, Á., Marcosd, E., Morenoag, J. M., Ramírezg, D. A., Sebastiàeh, M. T., Valladaresi, F., and Williamsj, D. G.: The stable isotope ecology of terrestrial plant succession, Plant Ecology \& Diversity, 4, 117-130, 2011.

Robinson, D.: $\delta^{15} \mathrm{~N}$ as an integrator of the nitrogen cycle, Trends Ecol. Evol., 16, 153-62, 2001.

Schjoerring, J. K., Husted, S., Mäck, G., and Mattsson, M.: The regulation of ammonium translocation in plants, J. Exp. Bot., 53, 883-890, 2002.

Schulze, E. D., Williams, J., Farquhar, G. D., Schulze, W., Langridge, J., Miller, J. M., and Walker, B. H.: Carbon and nitrogen isotope discrimination and nitrogen nutrition of trees along a rainfall gradient in northern Australia, Aust. J. Plant Physiol., 25, 413-425, 1998.

Sharpe, R. R. and Harper, L. A.: Apparent atmospheric nitrogen loss from hydroponically grown corn, Agron. J., 89, 605-609, 1997.

Simpson, R. J.: Translocation and metabolism of nitrogen: whole plant aspects, Dev. Plant Soil Sci., 19, 71-96, 1986.

Sintermann, J. and Neftel, A.: Ideas and perspectives: on the emission of amines from terrestrial vegetation in the context of new atmospheric particle formation, Biogeosciences, 12, 3225-3240, doi:10.5194/bg-12-3225-2015, 2015.

Sivak, M. N. and Walker, D. A.,: Photosynthesis in vivo can be limited by phosphate supply, New Phytol., 102, 499-512, 1986.

Sun, Y, Gu, L., Dickinson, R. E., Norby, R. J., Pallardy, S. G., and Hoffman, F. M.: Impact of mesophyll diffusion on estimated global land $\mathrm{CO}_{2}$ fertilization, P. Natl. Acad. Sci., 111, 1577415779, 2014.

Szpak, P.: Complexities of nitrogen isotope biogeochemistry in plant-soil systems: implications for the study of ancient agricultural and animal management practices, Frontiers in Plant Science, 5, doi:10.3389/fpls.2014.00288, 2014.

Tcherkez, G.: Natural ${ }^{15} \mathrm{~N} /{ }^{14} \mathrm{~N}$ isotope composition in $\mathrm{C} 3$ leaves: are enzymatic isotope effects informative for predicting the ${ }^{15} \mathrm{~N}$ abundance in key metabolites?, Funct. Plant Biol., 38, 1-12, 2011.

Thornton, P. E., Lamarque, J. F., Rosenbloom, N. A., and Mahowald, N. M.: Influence of carbon-nitrogen cycle coupling on land model response to $\mathrm{CO}_{2}$ fertilization and climate variability, Global Biogeochem. Сy., 21, 1-15, 2007.
Vitousek, P. M.: Beyond global warming: ecology and global change, Ecology, 75, 1861-1876, 1994.

Vitousek, P. M., Porder, S., Houlton, B. Z., and Chadwick, O. A.: Terrestrial phosphorus limitation: mechanisms, implications, and nitrogen-phosphorus interactions, Ecol. Appl., 20, 5-15, 2010.

Wang, L., Okin, G. S., Wang, J., Epstein, H., and Macko, S. A.: Predicting leaf and canopy ${ }^{15} \mathrm{~N}$ compositions from reflectance spectra, Geophys. Res. Lett., 34, doi:10.1029/2006GL028506, 2007.

Wang, N., Gao, J., Zhang, S. Q., and Wang, G. X.: Contemporary problems of ecology, Variations in leaf and root stoichiometry of Nitraria tangutorum along aridity gradients in the Hexi Corridor, northwest China, Contemp. Prob. Ecol., 7, 308-314, 2014.

Webb, B. and Adeloju, S. B.: Evaluation of some wet digestions methods for reliable determination of total phosphorus in Australian soils, Microchem. J., 111, 47-52, 2013.

Werner, R. A. and Schmidt, H. L.: The in vivo nitrogen isotope discrimination among organic plant compounds, Phytochemistry, 61, 465-484, 2002.

Wetselaar, R. and Farquhar, G. D. Losses of nitrogen from the tops of plants, Adv. Agron, 33, 263-302, 1980.

Wigand, C., McKinney, R. A., Cole, M. L., Thursby, G. B., and Cummings, J.: Varying stable nitrogen isotope ratios of different coastal marsh plants and their relationships with wastewater nitrogen and land use in New England, USA, Environ. Monit. Assess., 131, 71-81, 2007.

Yoneyama, T. and Kaneko, A.: Variations in the natural abundance of ${ }^{15} \mathrm{~N}$ in nitrogenous fractions of komatsuna plants supplied with nitrate, Plant Cell Physiol., 30, 957-962, 1989.

Yoneyama, T., Ito, O., and Engelaar, W. M. G. H.: Uptake, metabolism and distribution of nitrogen in crop plants traced by enriched and natural ${ }^{15} \mathrm{~N}$ : progress over the last 30 years, Phytochem. Rev., 2, 121-132, 2003.

Zhang, J., Gu, L., Bao, F., Cao, Y., Hao, Y., He, J., Li, J., Li, Y., Ren, Y., Wang, F., Wu, R., Yao, B., Zhao, Y., Lin, G., Wu, B., $\mathrm{Lu}, \mathrm{Q}$., and Meng, P.: Nitrogen control of ${ }^{13} \mathrm{C}$ enrichment in heterotrophic organs relative to leaves in a landscape-building desert plant species, Biogeosciences, 12, 15-27, doi:10.5194/bg-12-152015, 2015. 